Nikolai N. NePEJVODA

\title{
Formalization as the Immanent Part of Logical Solving
}

\author{
Nepejvoda Nikolai Nikolaevich \\ Ailamazyan Program System Institute of RAS \\ Pereslavl-Zalessky, Yaroslavl Region, 152020, Russian Federation. \\ E-mail: nnn@nnn. botik.ru
}

The work is devoted to the logical analysis of the problem solving by logical means.

It starts from general characteristic of the applied logic as a tool:

1. to bound logic with its applications in theory and practice;

2. to import methods and methodologies from other domains into logic;

3. to export methods and methodologies from logic into other domains.

The precise solving of a precisely stated logical problem occupies only one third of the whole process of solving real problems by logical means. The formalizing precedes it and the deformalizing follows it.

The main topic when considering formalization is a choice of a logic. The classical logic is usually the best one for a draft formalization. The given problem and peculiarities of the draft formalization could sometimes advise us to use some other logic.

If axioms of the classical formalization have some restricted form this is often the advice to use temporal, modal or multi-valued logic. More precisely, if all binary predicates occur only in premises of implications then it is possible sometimes to replace a predicate classical formalization by a propositional modal or temporal in the appropriate logic. If all predicates are unary and some of them occur only in premises then the classical logic maybe can replaced by a more adequate multi-valued. This idea is inspired by using Rosser-Turkette operator $J_{i}$ in the book [22]. If we are interested not in a bare proof but in construction it gives us it is often to transfer to an appropriate constructive logic. Its choice is directed by our main resource (time, real values, money or any other imaginable resource) and by other restrictions. Logics of different by their nature resources are mutually inconsistent (e.g. nilpotent logics of time and linear logics of money).

Also it is shown by example how Arnold's principle works in logic: too "precise" formalization often becomes less adequate than more "rough".

Keywords: applied logics, formalization, choice of logic

(C) Nikolai N. Nepejvoda 


\section{Introduction}

There is a long and hard way to reach relatively full and systematic description of problem solving by logic. But miles begins with one step.

This work is the first in series of two devoted to holistic analysis of problem solving by formal logical methods. We don't separate purely logical parts from informal ones. Aspects are stressed which are usually relatively weakly investigated: the choice of a logic during formalization; the correspondence between draft and working formalisms.

This paper is mainly methodological. Its results are the first steps to systematization and comprehension knowledge on problem solving process from the point of view of current situation in formal logic: a lot of heterogenous formalisms.

\section{Applied logic}

The applied logic [49] is a branch of the logic. It positions itself and the whole Logic Science as a bridge between mathematics, computer science, humanities and practice. Its main goals are the following:

1. to state ties and mutual understanding between logics and other domains of science and practice;

2. to comprehend methodological and logical aspects of other domains and adaptation them into logics;

3. to borrow and to adopt useful methods of other domains into logics;

4. to grasp existing and possible practical and applied potentials of theoretical logics;

5. to criticize practitioners from the high level logical point of view and logicians form the high level practical point of view.

Let us unfold each point.

1. Establishing ties. Languages and reasoning manners of modern logic and of majority other scientific and practical domains are very different in their paradigms. It is a fine theoretical and important practical task to connect together dissimilar paradigms. Usually it demands to reformulate some key notions in a more abstract manner.

EXAMPLE 1. Let us now consider the problem of infinitesimals and infinite large values in the calculus. These notions are declared ill by mathematicians at the middle of XIX age. Though physicists and practitioners continued to use them fruitfully. 
These phenomena had been re-substantiated by A. Robison (1961, [55] revised edition). He used high level paradigm of model theory discarding all concrete data types. Robinson's discovery leads to fundamental methodological consequences (this appears often when the level of notions is upgraded). His student Luxemburg [34, 35] proved that the statement "Logically impossible that infinite can be a part of finite" is false, which leads to the alternative set theory [66]. Russian translation of this book contains a fine methodological preface made by Belyakin [6].

EXAMPLE 2. It is very hard to rise the level of notions correctly. This can be shown on example of ill formed set theory $\mathbf{Z F}$. It have arised as a reaction of pure mathematicians on "restriction of their freedom of speech" by the type theory of B. Russel [67]. Principia provides a correct method to avoid paradoxes in the set theory: to write down types of all data and not to mix them arbitrarily. Computing forces many mathematicians to do this but initially they attempted to preserve usual inaccuracy when upgrading level of notions. High levels are very severe for consistency and justifying. And they avenged. A contradiction in $\mathbf{Z F}$ with the strongly inaccessible cardinal had been found by two completely different ways (Belyakin, Kiselev [7, 24, 25]). Hence it is impossible to speak about truth of set-theoretic statements in the natural model of $\mathbf{Z F}$ (which requires that cardinal). $\mathbf{Z F}$ is almost inconsistent and the bad guy is here not the axiom of choice but the axiom schema of replacement allowing one to mix arbitrary objects ${ }^{1}$.

2. Methodologies transfer. Methodology diverges from a method like a common idea from its concrete realization. The first successful transfer of useful methodology and paradigm into logic was Mill's invention of an inductive logic [38]. This is a very hard task as showed e.g. the transparent logic [63]. It is unsuccessful because it directly imported constructions of $\lambda$ calculus. Mathematics gives the methodology to the mathematical logic. As shown before, ML often forgets its second parent becoming simply a branch of pure mathematics.

3. Transferring methods. Logic started when methods of geometry were transferred to reasoning analysis. Aristoteles used letter notations for propositional variables. Definition of inference as "a discourse in which, certain

\footnotetext{
${ }^{1} \mathrm{~A}$ reaction of the mathematical society on Belyakin and Kiselev results was predictable. First these results were blocked by reviewers (often with resolutions like: "Errors are not found but this result is disgusting", "It cannot be that the whole branch of science 50 years studied nonsence". After this fails full silence and disregarding. New works using large cardinals are published now. This situation is a consequence of the global corruption of science induced by the cult of success and forgetting the notion of honour.
} 
things being laid down, something different from the posita happens from necessity through the things laid down". (Topics, book 1, ch. $1[3])^{2}$.

Algebra was incomparable as a source of methods for a long time. Britain school of XIX age built strong foundations for logic [40, 11, 12]. Using algebraic methods together with set-theoretical is the source of original methodology of mathematical logic. Now computer science is a new source of ideas and methods.

4. Seeing possibilities. Here are lots of good examples. We mention the two most important ones from heroic for logic 30ths: undecidability (Gödel [19]); applying boolean algebra to synthesis of electronic schemata (Shestakov $[59,60])$.

5. Criticism. Why criticism but not justification? If we pose a goal to justify the given decision a scientist plays the role of a priest praying but not penetrating the essence ${ }^{3}$.

An excellent and striking example of tough criticism is given in Example 2. ZF which is almost standard in modern mathematic become very dubious. This example needs some extra methodological analysis.

There is a phenomenon of conceptual contradictions revealed in the theory of nonformalizable notions [41]. Theory is consistent by itself. But its slight and natural modifications make it inconsistent because some statements or notions interfere. An example are here axioms of powerset and of substitution in $\mathbf{Z F}$ ). Logic can reveal conceptual contradictions. This is important for high types where "common sense" and "intuition" are misleading too often. Generally when the level of notions becomes higher then we have less "freedom" and more bad consequences of hidden conceptual contradictions. On the level of reflexes even direct contradiction can be often easily bypassed.

\section{Logical process}

Fig. 1 illustrates the whole process solving a problem logically. Two of the three transformations (vertical arrows) are poorly represented in logical works. Numerous remarks on formalization process usually relate to most obvious parts of it. State of arts with deformalization is "almost ignoring".

\section{Formalization}

There are four components of this process.

\footnotetext{
${ }^{2}$ It is not related with the form of syllogism; English translation is ill here because inserted "syllogism" instead of e.g. "demonstration".

${ }^{3}$ As noted Sei-Shonagon here a gracious sight and a pleasing voice pronouncing complex and nice mantras are needed [57].
} 


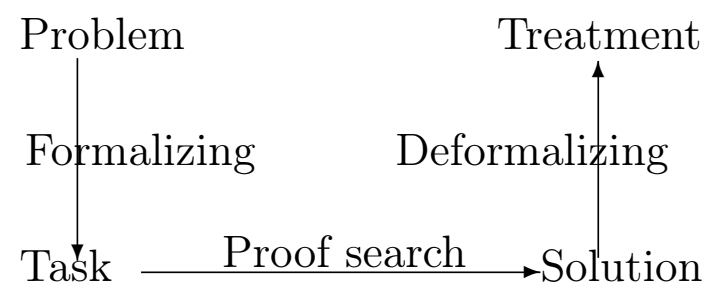

Рис. 1. Solving process

1. Choice of a logic (classical, multivalued, constructive (which?), modal or temporal, other $)^{4}$.

2. Replacing notions by terms.

3. Omitting natural properties hindering our formalization.

4. Granting acceptable time and resource spending to find a solution.

\subsection{Choice of a logic}

This aspect is poorly enlightened in the existing logical works. Moreover it looks too hard to try transferring here methods of other branches of science. Usually a logic is chosen by the following arguments.

1. Tradition.

2. Problem and condition on used tools and resources.

3. Peculiarities of the draft formalization.

Let us give preliminary directions how to choose a logic. The main aspect is here a clear insight of our problem as a goal in given conditions, restrictions and limits. Roughly speaking there are the three types of goals.

1. To construct.

2. To describe.

3. To state new properties of earlier described entities.

\footnotetext{
${ }^{4}$ This is not a classification. Standard list of Congress on Universal Logic [1] also doesn't: modal logics; substructural logics; linear logics; relevant logics; fuzzy logics; non-monotonic logics; paraconsistent logics; intensional logics; temporal logics; many-valued logics; high order logics; free logics.

It is dissatisfactory for us and does not meet logical demands (mixed notions of different levels; intersecting notions).
} 
If there is a description which is to be investigated then its logic would be changed only by very strong reasons. Thus here a tradition is a crucial argument. But in mathematics and computer science is well known that sometimes to change a representation for a formally isomorphic one is a big step to invention.

Goals and principles of description and construction are very different. Thus first coordinate to classify a logic is its place on the scale descriptive $\rightarrow$ constructive. A purely descriptive logic can express complex properties but it cannot give a realizable construction. A purely constructive one allows us to extract an effective construction realizable by our resource limits. A general case is a mixed one. For example the classical logic sometimes can give a construction and sometimes is purely descriptive.

Constructions and descriptions can take into account resources explicitly or implicitly. This characteristic also is not binary.

A logic can be first-order (e.g. classical esp. propositional). Another logic can demand in its natural semantics higher order essences (e.g. intuitionistic realizability for the propositional logic). This is another opposition. It is not exclusive also. E.g. the intuitionistic logic has formally first-order semantics of Kripke models.

And the last characteristic is whether exists a notion of a logical value and whether the set of values is fixed. There are no logical value for a formula in realizability and in possible worlds semantics. Maybe this characteristic is binary.

Let us consider from this point of view various logics to give some directions how to choose one.

\section{Classical}

The classical logic has the best formalization, transformations of sentences and proof search techniques. Those techniques are widely known. By these reasons the classical logic is usually chosen by tradition. The first draft of formalization is reasonably almost always made by the classical logic. But it is necessary to remember a law of programming: the first draft is made to be discarded completely later. This method is worth to be borrowed by logicians. There is one more strong reason why to use the classical logic first. It had been shown in theory of nonformalizable notions $[41,42]$ that in a system of such notions the best logic to formalize a given single state of their interrelations is classical one. And last but not least a form of a classical theory can advise a non-classical logic now describing a lot of states of (nonformalizable) notions or simply more effective in the particular case.

Limitations of the classical logic are the necessary consequences of its accomplishments.

The classical logic has maximally strong epistemological assumptions. 
1. World is stable;

2. all notions are well defined and coarsed down to binary;

3. we know all (in principle): $A \vee \neg A$.

Characteristics of the classical logic are: descriptivity in common case; constructivity in many particular cases; full ignoring of resource limits and demands on admissible tools; first order and possibility of natural extension to higher orders; minimality of logical values set; undecidability of predicate logic; NP-completeness of propositional one.

\section{Modal and temporal}

This class of logics now is an important practical tool (first of all in verification of program models $[13,54,65])$. Say a typical formula in verification of a program model is [13]

$$
\mathrm{AG}(R e q \rightarrow \mathbf{A F} A c k) .
$$

AG means "in each point of each computation starting in this state", AF is "in a some point of each computation starting in this state". This formula can be read

There is a moment of acknowledgement for each demand.

This formula cannot be expressed in the classical first order logic and in standard modal logics. It showed that sometimes we can replace predicates and sometimes second order formulas by a propositional form in an adequate logic. And those propositional statements have a decision algorithm of acceptable complexity. A process of accurate design and choice of an applicable logic is described in [13]. Let us try to understand why here was a success.

When verification problems are formulated by the classical logic, binary and second order predicates are used in limited way: only in premises. Conclusions contain only unary predicates describing demanded properties of program states. Thus there is a hypothesis. Modal or temporal logic can be successfully applied if classical formulas have some limited form.

The main characteristics of logics of these classes. Descriptivity (attempts to crossbreed modality and time with constructive logics lead to monsters); successful implicity when expressing conditions on models; good accommodation to conditions on multiworld structures and execution paths; full refusal from universality; full refusal from fixed set of logical values; possibility to express high order conditions in a propositional form.

\section{Constructive}

Constructive logics are needed when we find not only a bare proof but its realization by the given tools under the given limits of resources. So using them 
is forced by a problem and its context. Usually classical formalisms whether do not grant any construction or its extraction is too complex and the extracted construct is too clumsy and costly.

The most known constructive logic is intuitionistic one [26, 39, 53]. It is used in the system of demonstrative programming and proof checking AGDA [2]. Experiments (see e.g. [37]) showed an extremely high complexity of programming and demands for computational resources for relatively simple tasks. Thus the "universal" method again fails in praxis. A source of complexities is that the intuitionistic logic has the weakest demands on tools and resources. A computation is to be finite in time and memory but no limits are stated $[50,45,46,47]$. And one more obstacle: complexity of the intuitionistic propositional logic is higher than of the classical one [62].

So it is necessary to choose a constructive logic for the given class of problems and restrictions.

An excellent example is the infon logic (PIL-logic) of Gurevich [20, 9]. Formally this is a linear time decidable fragment of the intuitionistic logic. But it has a valuable system of realizations for problems of information search and security. Here a reduced form of the deduction rule is sufficient:

$$
\frac{B}{A \Rightarrow B} \text {. }
$$

Intuitionistic and infon logics demand higher order functions for their realizability semantics.

Another example is the interfaces logic of Kochurov [27, 30, 28, 29], as a first order constructive logic. It is restricted by constructing nets of objects or actions. There are the following rules for implication in it:

$$
\begin{gathered}
\frac{A \Rightarrow B, B \Rightarrow C}{A \Rightarrow(B \Rightarrow C)} \frac{A \Rightarrow(B \Rightarrow C)}{A \Rightarrow B, B \Rightarrow C} \frac{A \Rightarrow B, B \Rightarrow C}{(A \Rightarrow B) \Rightarrow C} \frac{(A \Rightarrow B) \Rightarrow C}{A \Rightarrow B, B \Rightarrow C} \\
\frac{A \Rightarrow B, A \Rightarrow C}{A \Rightarrow(B \& C)} \frac{A \Rightarrow(B \& C)}{A \Rightarrow B, A \Rightarrow C} \frac{A \Rightarrow C, B \Rightarrow C}{(A \& B) \Rightarrow C} \frac{(A \& B) \Rightarrow C}{A \Rightarrow C, B \Rightarrow C}
\end{gathered}
$$

A theory defines the net of all objects and actions existing in a system. A realization is a subnet from members of premiss to members of conclusion.

There is one more important aspect of constructive logics: The Main Resource [48, 51].

Essence of the time is its non-invertibility and foundness. We cannot spend nothing because we are spending time. Every process spending time gives necessarily a fatal error (death) in a finite time. Thus every sequence of actions is finite. Because the fatal error can be described algebraically as zero an algebraic characteristic of action space is to be nilpotent: each composition 
of actions in finite number of steps gives 0 . So the logic of noninvertible actions is called nilpotent $[52,44]$.

Due to non-invertibility of time each loop which is logically correct will end in the finite number of steps. This is expressed by the rule

$$
\frac{A \vee B \Rightarrow B \vee C}{A \Rightarrow C}
$$

Here $A$ is the condition to start a loop (precondition), $B$ is the condition which holds at the beginning of each step of the loop (invariant), $C$ is the postcondition. Disjunction $\vee$ can be interpreted classically if elementary properties are decidable. Implication is treated constructively as existence of a program. Nilpotent logic is linear time decidable. Rule (3) forces that law of identity $A \Rightarrow A$ is inacceptable and even false here. Moreover there is a rule of excluded stagnation

$$
\frac{A \Rightarrow A}{\neg A}
$$

Development of nilpotent logic leads to the notion of a proof as a graph with possible branches and loops. A proof by the natural deduction for nilpotent logic allows "vicious circles". The restriction is here that each loop must contain an application of modus ponens

$$
\frac{A \quad A \Rightarrow B}{B} .
$$

It is interpreted as application of an action in a state where $A$ holds transferring into a state where $B$ holds. Loop containing proofs in a provability logic [58] together with similar proofs in nilpotent logics lead to a methodological assumption.

The abstract property that there are nilpotent steps in a proof (each sequence is finite) then we can use proofs with loops if in each loop there is a nilpotent step.

Nilpotent logic is first-order and the main resource is implicit. Implicit representation of time in the nilpotent logic (and analogous peculiarities of practical time logic) allows us to state a claim. In logic implicit representation is often better than explicit. Another argument for this claim that many logics where resources were introduced explicitly become practically useless.

Girard's linear logic has money as the main resource [14, 17, 18]. Unfortunately even its propositional part is undecidable because it includes all possible connectives but not necessarily needed [33]. Linear and nilpotent logics are mutually inconsistent. $A \Rightarrow A$ is accepted in linear ones because it is possible not to spend money ${ }^{5}$.

\footnotetext{
${ }^{5}$ Make yourself conclusions about "Time is money".
} 


\section{Intermediate case}

Some classical theories are really constructive. It suffices that a theory is full and decidable. A stronger form of constructiveness arises if there is an quantifier elimination algorithm. Then each existing object can be named by internal means of the theory and its characteristic property can be computed algorithmically using existence theorem. But usually such theories have very high level of computational complexity. Good examples are here the elementary geometry and the elementary algebraic theory of real numbers [36, 61].

Thus there is a problem: like Gurevich, to construct simply decidable constructive logics for these theories.

One more case. Category logics are a kind of constructive from our point of view. They give categorical constructs for categorical problems (for example to construct values of dotted arrows, limits and colimits, adjoints).

R. Burstall [8] noted that the category theory is in essence constructive one. Moreover, it gives practical higher order constructs for computer science ${ }^{6}$. Development of category logics reaffirms Burstall's concepts (see Lambek, Bell, Vasyukov $[32,5,64])$

\section{From classical to non-classical}

Now it is possible to give some advices how to use non-classical logics during problem solving. The advices, of course, now are a bit eclectic.

If the goal of our work is to find a program or a composition of actions, it may be very fruitful to transfer to constructive logic (if it is well chosen).

If binary predicates are used only in premises and in a limited way it is possible that we can find an appropriate modal or temporal logic.

If all predicates are unary and some of them occur only in premises then the classical logic maybe can replaced by a more adequate multi-valued. This idea is inspired by using Rosser-Turkette operator $J_{i}$ in the book [22].

EXAMPLE 3. Let us consider a partial case how to transfer from classical logic to propositional modal one. Let we can classify variables into two types: worlds and props such that the following holds.

There is a single binary predicate and in each its occurrence the first argument is a world and the second is a prop: $\operatorname{SAT}(w, p)$.

There are several unary predicates and unary functors from props to props. There are no other predicates and functors using or giving props.

Some axioms can be transformed to:

$$
\forall p(P(p) \supset \forall w(\operatorname{SAT}(w, p) \equiv \mathfrak{A}(w, p))) .
$$

Here $p$ is a prop, $w$ is a world, $\mathfrak{A}$ is arbitrary.

\footnotetext{
${ }^{6}$ Unfortunalely these methods are still not used excluding some experimental systems thrown away immediately after generating some scientific publications and Ph.D. theses.
} 
Then semantics of the strong implication can be expressed by a formula

$$
\forall p\left(I(p) \supset \forall w\left(\begin{array}{c}
\operatorname{SAT}(w, p) \equiv \forall v(R(w, v) \& \\
\operatorname{SAT}(v, \operatorname{Pre}(p)) \supset \operatorname{SAT}(v, \operatorname{Con}(p)))
\end{array}\right)\right)
$$

Here $I(p)$ can be understood as " $p$ is an implication", $\operatorname{Pre}(p), \operatorname{Con}(p)$ then disassemble it for premiss and conclusion. If there is a such axiom or theorem in our theory it is reasonable to try to transform some other axioms such that they will describe modal connectives and then change a logic.

\subsection{Notions change}

This aspect of formalization is relatively well and adequately described (see say a classical book [31]). Of course there arise new fine points. For example an important new branch is formalizing of nonformalizable notions [21, 10, 41, $42,43,15]$. Nonformalizability is the logical characteristic of living. But during each formalization living notions are replaced by their monuments ${ }^{7}$.

\subsection{Elimination of disturbing}

This aspect of formalization is described excellently in works on applied mathematics and physics. See the classical treatise of lord Kelvin [23]. This action is somewhat Jesuitic called "abstraction" or "distraction". But abstraction assumes lifting of notion level, transfer from concrete real notions to ideal notions or from low-level ideal notions to high level essences. But for example "abstraction from influence of other planets excluding Jupiter" is lowering of model level. Here can be only distraction. In the most expressive form this was formulated by Chebyshov in his famous lecture "Mathematical foundations of clothes cutting": "We accept for simplicity that a human body is a sphere".

Distracting is reflected in logical works a bit less narrowly. But here it reveals its pure forms not vestured by euphemisms like "small" or "insignificant". Let consider a simple logical example.

"Prof claims that students using Ipad become more stupid".

$$
\text { Пп } \Leftrightarrow \forall x(\text { Ст }(x) \& \mathrm{CA}(x) \Rightarrow \mathrm{T}(x)) .
$$

This translation is almost precise but it is not handy for hand construction (say) of a semantic tableaux. Consider now more complex proposition.

"Prof claims that students using Ipad become more stupid but student Sherbinin argues".

To test this sentence by hand for non-contradiction we can translate its part less precisely but more handy to our particular task:

\footnotetext{
${ }^{7}$ Remember historical anecdote. When Heavyside counted to be dead he went at night from his hideout to the new monument devoted to him and said: "I do not look like me".
} 


$$
\begin{aligned}
& \left(\Pi_{\Pi} \Rightarrow \forall x\left(\mathrm{C}_{\mathrm{T}}(x) \& \mathrm{CA}(x) \Rightarrow \mathrm{T}(x)\right)\right) \& \\
& \quad\left(\Pi_{\omega} \Rightarrow \exists x(\mathrm{CT}(x) \& \mathrm{CA}(x) \& \neg \mathrm{T}(x))\right)
\end{aligned}
$$$$
\Rightarrow \neg \Pi \text { } \vee \neg \Pi ш \text {. }
$$

If we will test the disjunction of parts it is better to omit another part of equivalency:

$$
\begin{aligned}
& (\forall x(\mathrm{CT}(x) \& \mathrm{CA}(x) \Rightarrow \mathrm{T}(x)) \Rightarrow \text { Пп)\& } \\
& (\exists x(\mathrm{CT}(x) \& \mathrm{CA}(x) \& \neg \mathrm{T}(x)) \Rightarrow \text { Пш) }
\end{aligned}
$$

$$
\Rightarrow \Pi \Pi \vee \text { Пш. }
$$

Note that in each case we weakened the premiss thus if we find a solution it remains valid for full translation.

V. Arnold formulated in his excellent lecture [4] the main principle of good formalization: say as few as possible.

When working with a ready formalism it is necessary to keep in mind another warning of Arnold from [4]: if we get a result by a "precise method" it is to be rechecked by another method ${ }^{8}$, because omitted features will often avenge recklessly and surprisingly. Say, optimal decision (by some precise criterion) almost always turns out to be bad or even fatal in reality ${ }^{9}$.

EXAMPLE 4. Our institute develops a neuron net to give advices to medics. Its first variant was learned by more than hundred thousands real examples and has almost 100 evaluation criteria. After more than 1000 steps of training it gives an excellent for neuron nets result: $98 \%$ of correct answers. After analysis it was stated that $98 \%$ of doctors' decisions were given mechanically using socalled standards of treatment. Thus the net simply restored these standards (and the admissible number of non-standard decisions prescribed by them is precisely $2 \%$ ).

\subsection{Effectiveness}

Effectiveness control can be performed before and during formalization. In many cases efficiency is to be the decisive criterion of formalization choice and especially changing. This is an important rule in computer science and would be the same in logics $[56,16]$.

\section{Conclusion}

This work represents the first part of the plenary lecture on 10th Smirnov Readings. The second one will be published in the next issue of this journal

\footnotetext{
${ }^{8}$ Possibly by imprecise and informal.

${ }^{9}$ Inoptimality and nonformalizability are characteristics of living; optimization almost always leads to death when situation changes radically.
} 
and is devoted to deformalization. Of course when rewritten into English text lost some fine aspects of Russian original and became more dry.

Extended Russian version of these two papers will be published in "Program Systems and Applications" as a single paper.

\section{References}

[1] "6th World Congress and School on Universal Logic", [https://www.unilog.org/vichy2018 accessed on 08.08.2017].

[2] "The AGDA Wiki", [http://wiki.portal.chalmers.se/agda/pmwiki.php accessed on 08.08.2017].

[3] Aristotle. The Complete Works of Aristotle: The Revised Oxford Translation. Princeton, N.J: Princeton University Press, 1984.

[4] Arnold, V.I. "Zhestkie" $i$ "myagkie» matematicheskie modeli" ["Hard" and "soft" mathematical models]. Moscow: MCNIMO, 2004. 32 pp. (In Russian)

[5] Bell, J. L. "The Development of Categorical Logic". In: Handbook of Philosophical Logic, Vol. 12. Springer: 2005.

[6] Belyakin, N.V. "Ot redaktora perevoda" [Editor's Notes]. in: Vopenka P. Al'ternativnaya teoriya mnozhestv: novyj vzglyad na beskonechnost [Alternative set theory: new pointo of view on infinity]. Novosibirsk: Izdatelstvo Insutituta Mastematiki, 2004. pp. 11-29. (in Russian)

[7] Belyakin, N.V. "O nesushchestvovanii bol'shih kardinalov" [On non-existence of large cardinals], Chislo [Number], Moscow: MAKS Press, 2009. pp. 169-192. (In Russian)

[8] Burstall, R.M. "Electronic category theory". In: Dembiński P. (eds) Mathematical Foundations of Computer Science 1980. MFCS 1980. Lecture Notes in Computer Science, Vol. 88. Berlin, Heidelberg: Springer, 1980.

[9] Cotrini, C., Gurevich, Yu. "Basic primal infon logic", Journal of Logic and Computation, 2016, Vol. 26, Issue 1, pp. 117-141.

[10] Belyakin, N.V., Zhevlakova, E.K. "Operaciya diagonalizacii v voprosno-otvetnyh sistemah" [Diagonalization in QA systems], Vychislitelnye sistemy [Computing systems], 1976, No. 67, pp. 113-126.

[11] Boole, G. The Mathematical Analysis of Logic, Being an Essay towards a Calculus of Deductive Reasoning. London, England: Macmillan, Barclay \& Macmillan, 1847.

[12] Boole, G. The Laws of Thought, facsimile of 1854 edition, with an introduction by John Corcoran. Buffalo: Prometheus Books, 2003.

[13] Clarke, E. M., Grumberg, O., Peled, D. Model checking. MIT Press, 2010, pp. 330.

[14] Di Cosmo R., Miller, D. "Linear Logic", The Stanford Encyclopedia of Philosophy (Winter 2016 Edition), ed. by Edward N. Zalta, [https://plato.stanford.edu/archives/win2016/entries/logic-linear/ accessed on 08.08.2017]. 
[15] Finn, V.K. Iskusstvewnnyj intellekt: metodologiya,primeneniya, filosofiya [Artificial intelligence: methodology, applications, philosophy]. Moscow: KRASAND, 2011, 448 pp. (In Russian)

[16] Fortnow, L.; Homer, S. "A Short History of Computational Complexity", Bulletin of the EATCS, 2003, Vol. 80, pp. 95-133.

[17] Girard, J.-Y. "Linear logic", Theoretical Computer Science, 1987, Vol. 50, pp. $1-102$.

[18] Girard, J.-Y. "Light Linear Logic", Information and Computation, 1998, Vol. 143, No. 2, pp. 175-204.

[19] Gödel, K. " Über formal unentscheidbare Sätze der Principia Mathematica und verwandter Systeme, I", Monatshefte für Mathematik und Physik, 1931, Vol. 38, pp. 173-198.

[20] Gurevich, Yu., Neeman, I. "Infon logic: the propositional case", ACM Transactions on Computation Logic, January 2011, Vol. 12, Issue 2, No. 9, pp. 1-28.

[21] Collected Papers of Stig Kanger with Essays on his Life and Work, 2 vol., eds. by Ghita Holmström-Hintikka, Sten Lindström \& Rysiek Sliwinski. Dordrecht (NL): Kluwer Academic Publishers, 2001.

[22] Karpenko, A.S. Razvitie mnogoznachnoj logiki [The development of multi-valued logic]. Moscow: LKI Publishers, 2014. 448 pp. (In Russian)

[23] Lord Kelvin, Tait, P.G. Treatise of natural philosophy part I, II. Cambridge: University Press, 1912.

[24] Kiselev, A.A. Nedostizhimost' $i$ subnedostizhimost: monografiya v dvuch chastyah. Ch. 1 [Inaccessibility and subinaccessibility. In two parts. Part 1]. Minsk: BGU Edition, 2011. 113 pp. (In Russian)

[25] Kiselev, A.A. Nedostizhimost' $i$ subnedostizhimost: monografiya v dvuch chastyah. Ch. 1 [Inaccessibility and subinaccessibility. In two parts. Part 2]. Minsk: BGU Edition, 2011, 154 pp. (In Russian)

[26] Kleene, S.C. Introduction to Metamathematics. N. Y.: 1952.

[27] Kochurov, E.V. "Konstruktivnyj sintez pol'zovatel'skih interfejsov Webprilozhenij" [Constructive synthesis of user interfaces of Web-applications], Programmnye sistemy: teoriya $i$ prilozheniya [Program Systems: Theory and Applications], 2013, Vol. 4, No. 18, pp. 3-25. (In Russian)

[28] Kochurov, E.V. "Ob odnoj konstruktivnoj logike postroenij na grafah" [On one constructive logic of graph constructions], Devyatye smirnovskie chteniya po logike, Moscow: Sovremennye tetradi, 2015, pp. 22-24. (In Russian)

[29] Kochurov, E.V. "Primenenie logiki postroenij na grafah $\mathrm{k}$ ispolneniyu modelelj biznes-processov" [Application of the graph constructions logic to businessprocess modelling], Programmnye sistemy: teoriya $i$ prilozheniya [Program Systems: Theory and Applications], 2015, Vol. 6, No. 4, pp. 359-366. (In Russian)

[30] Kochurov, E.V., Nepejvoda N.N., Grigotrevskij I.N. "Zamechaniya o logikah postroenij na grafah i ih primenenii" [Notes on logics of graph constructions and their applications], Sbornik nauchnyh dokladov Vtoroj mezhdunarodnoj nauchno- 
prakticheskoj konferencii 'Tehnicheskie nauki: teoriya, metodologiya i praktika' [Collection of scientific presentations. Second international scientific-practical conference 'Technical science: theory,methodology and practice'], Moscow: ANO 'Scientific Survey', 2014. (In Russian)

[31] Kohen, M.R., Nagel, E. An Introduction to logic and scientific method. Harcourt: Brace and Co. 2nd ed. 1993.

[32] Lambek, J., Scott, P.J. Introduction to Higher Order Categorical Logic. Cambridge: University Press, 1986.

[33] Lincoln, P., Mitchell, J., Scedrov A., Shankar, N. "Decision problems for propositional linear logic", Annals of Pure and Applied Logic, 1992, no 56, pp. $239-311$.

[34] Luxemburg, W.A.J. Nonstandard Analysis, Lectures on A. Robinson's theory of infinitesimal and infinitely large numbers. Caltech Bookstore, 1962.

[35] Luxemburg, W.A.J. "What is Nonstandard Analysis?", American Mathematical Monthly, 1973, Vol. 80, pp. 38-67.

[36] Macintyre, A.J., Wilkie, A.J. "On the decidability of the real exponential field". In: Odifreddi P.G. Kreisel 70th Birthday Volume, CLSI, 1995.

[37] Meshveliani, S.D. "Programmirovanie vychislitel'noj algebry na osnove konstruktivnoj matematiki. Oblasti s razlozheniem na prostye mnozhiteli" [Programming of computer algebra by constructive mathematics. Domains with factorization], Programmnye sistemy: teoriya i prilozheniya [Program Systems: Theory and Applications], 2017, Vol. 8, no 1, pp. 3-46. (In Russian)

[38] Mill, J.S A System of Logic, Ratiocinative and Inductive. New York: Harper \& Brothers, 1874.

[39] Mints, G. A Short Introduction to Intuitionistic Logic. Kluwer, 2000.

[40] De Morgan, A. Logic: On the Syllogism and Other Logical Writings, ed. by P. Heath, Routledge, 1966.

[41] Nepejvoda, N.N. "O formalizacii neformalizuemyh ponyatiy: avtoproduktivnye sistemy teoriy" [Formalizing informalizable notions: autoproductive systems of theories], Semiotika i iniformatika [Semiotics and informatics], 1985, Vol. 25, pp. 46-93. (In Russian)

[42] Nepejvoda, N.N. "O formalizacii neformalizuemogo" [Formalizinfo informalizablr], Logicheskiye issledovasniya [Logical Investigations], 2001, Vol. 8, pp. 129-143. (In Russian)

[43] Nepejvoda, N.N. "Neformalizuemost kak logicheskaya harakteristika zhizni" [Informalizability as logical characteristic of life], Online journal 'Logical Studies', 1999, No. 3. (In Russian)

[44] Nepejvoda, N.N. "A constructive logic of program schemata on a decidable universe", Bulletin of the Section of Logic, 1988, Vol. 17, No. 3/4, pp. 138-145.

[45] Nepejvoda, N.N. "Konstruktivnaya matematika: obzor dostizheniy, nedostatkov i urokov. Chast' I" [Constructive mathematics: survey of susccesses, shortcomings 
and lessons. Part I], Logiceskie issledovaniya [Logical Investigations], 2001, Vol. 17, pp. 191-239. (In Russian)

[46] Nepejvoda, N.N. "Konstruktivnaya matematika: obzor dostizheniy, nedostatkov i urokov. Chast' II" [Constructive mathematics: survey of susccesses, shortcomings and lessons. Part II], Logiceskie issledovaniya [Logical Investigations], 2012, Vol. 18, pp. 157-181. (In Russian)

[47] Nepejvoda, N.N. "Konstruktivnaya matematika: obzor dostizheniy, nedostatkov i urokov. Chast' III" [Constructive mathematics: survey of susccesses, shortcomings and lessons. Part III], Logiceskie issledovaniya [Logical Investigations], 2014, Vol. 20, pp. 112-150. (In Russian)

[48] Nepejvoda, N.N. "O konstruktivnyh logikah" [On constructive logics], Sintaksicheskie $i$ semanticheskie issledovaniya neekstensionalnyh logik [Syntactic and semantic investigations of non-extensional logics], Moscow: Nauka, 1989, pp. 81-92. (In Russian)

[49] Nepejvoda, N.N. Prikladnaya logika [Applied logics]. Novosibirsk: NGUPress, 2000, 521 pp. (In Russian)

[50] Nepejvoda, N.N. Uroki konstruktivizma [Lessons of constructivism]. Heidelberg, 2011, 108 pp. (In Russian)

[51] Nepejvoda, N.N. "Vyzovy logiki i matematiki XX v. i 'otvet' na nih civilizacii" [Challenges of logics and mathematics of XX century and 'responce' on them of the civilization], Voprosy Filosofii [Problems of Philosophy], 2005, No. 8, pp. 118128. (In Russian)

[52] Nepejvoda, N.N. "Vyvody v forme grafov" [Proofs as graphs], Semiotika $i$ informatika [Semiotics and informatics]. Vol. 26. Moscow: VINITI, 1985. (In Russian)

[53] Van Oosten, J. "Realizability: a historical essay", Mathematical Structures in Comp. Sci., Vol. 12, No. 3, Cambridge University Press, 2002.

[54] Peled, D., Pelliccione, P., Spoletini, P. "Model Checking", Wiley Encyclopedia of Computer Science and Engineering, 2009.

[55] Robinson, A. Non-standard analysis, ed. by Revised. Princeton University Press, 1996.

[56] Sanjeev, A., Boaz, B. Computational Complexity: A Modern Approach. Cambridge, 2009.

[57] Sei Shonagon. The Pillow Book. London, England: Penguin Books, 2006.

[58] Shamkanov, D.S. "Circular proofs for the Gödel-Löb provability logic", Mathematical Notes, September 2014, Vol. 96, Issue 3-4, pp. 575-585.

[59] Shestakov, V.I. Nekotorye matematicheskiye metody konstruirivaniyac $i$ uproshcheniya dvuhpolusnyh elektricheskih shem klassa A [Some mathematical methods constructing and simplification of two-polar electricalk schemes of class A], Dr.Sc. Thesis, 1938. (In Russian)

[60] Shestakov, V.I. “ Algebra dvuhpolusnyh shem postroennyh isklyuchitel'no iz dvuhpolusnikov (algebra A-shem)" [Algebra of bipolar schemes builded only by 
bipolar elements (algebra of A-schemes)], Avtomatika i telemehanika [Automatics and telemechanics], 1941, No. 2, pp. 15-24. (In Russian)

[61] Solovay, R. M., Arthan, R. D., Harrison, J. "Some new results on decidability for elementary algebra and geometry", Annals of Pure and Applied Logic, December 2012, Vol. 163, Issue 12, pp. 1765-1802.

[62] Statman, R. "Intuitionistic Propositional Logic is Polynomial-Space Complete", Theoretical Computer Science, 1979, Vol. 9, No. 1, pp. 67-72.

[63] Tichý, P. The Foundations of Frege's Logic. Berlin and New York: De Gruyter, 1988. 333 pp.

[64] Vasyukov, V.L. Categorical Logic. Moscow: ANO Institute of Logic, 2005. 194 pp.

[65] Vizel, Y., Weissenbacher, G., Malik, S. "Boolean Satisfiability Solvers and Their Applications in Model Checking", Proceedings of the IEEE, 2015, Vol. 103, No. 11, pp. 2021-2035.

[66] Vopénka, P. Mathematics in the Alternative Set Theory. Leipzig, 1979.

[67] Whitehead, A.N., Russell, B. Principia Mathematica, 3 vols. Cambridge: Cambridge University Press, 1925-1927. (In Russian) 